\section{$\underset{\substack{\text { hommes } \\ \text { \& migrations }}}{ }$}

\section{Hommes \& migrations}

Revue française de référence sur les dynamiques

migratoires

$1285 \mid 2010$

L'appel du pied

\title{
Luis Sepulveda, L'Ombre de ce que nous avons été
}

Traduit de l'espagnol (Chili) par Bertille Hausberg. Edition Métailié, 150 pages, 17 euros

\section{Mustapha Harzoune}

\section{OpenEdition}

Journals

Édition électronique

URL : http://journals.openedition.org/hommesmigrations/1221

DOI : 10.4000/hommesmigrations. 1221

ISSN : 2262-3353

Éditeur

Musée national de l'histoire de l'immigration

Édition imprimée

Date de publication : 1 mai 2010

Pagination : 203

ISSN : 1142-852X

\section{Référence électronique}

Mustapha Harzoune, «Luis Sepulveda, L'Ombre de ce que nous avons été », Hommes \& migrations [En ligne], 1285 | 2010, mis en ligne le 29 mai 2013, consulté le 22 septembre 2020. URL : http:// journals.openedition.org/hommesmigrations/1221 ; DOI : https://doi.org/10.4000/

hommesmigrations.1221

Ce document a été généré automatiquement le 22 septembre 2020.

Tous droits réservés 


\title{
Luis Sepulveda, L'Ombre de ce que nous avons été
}

Traduit de l'espagnol (Chili) par Bertille Hausberg. Edition Métailié, 150 pages, 17 euros

\author{
Mustapha Harzoune
}

\section{RÉFÉRENCE}

Luis Sepulveda, L'Ombre de ce que nous avons été, Traduit de l'espagnol (Chili) par Bertille Hausberg. Édition Métailié, 150 pages, 17 euros

Santiago du Chili. Une nuit grise. Hivernale. Des hommes convergent vers un lieu de rendez-vous. "Plus gros, plus vieux, chauves et la barbe blanchie, ils projetaient encore l'ombre de ce qu'ils avaient été" écrit Luis Sepúlveda. À leur manière, en cette nuit du 15 au 16 juillet, ils sont là pour commémorer un événement. Cacho, Lucho et Lolo sont déjà arrivés. Ils attendent "le Spécialiste","L'Ombre", Pedro Nolasco Gonzalez. Manque de chance, Pedro, le maitre de cérémonie, le cerveau de cette ultime opération, est allongé raide mort sur un trottoir arrosé par la pluie. Une "fatalité verticale" vient de défoncer la boîte crânienne du bonhomme. Une scène de ménage entre Conception et Coco, son rêveur de mari, a provoqué une pluie de disques, de livres, de vidéos et surtout d'un antique et fatal tourne-disque Dual. Coco ne pourra que constater le décès de ce passant qui portait un vieux révolver sur lui. Sur cette trame, vient se greffer l'enquête sur la mort de Pedro menée par Crespo, un vieil inspecteur et sa jeune collègue. Lui a connu le temps de la dictature, un mot "banni" des dictionnaires aujourd'hui. Elle, toute fraîche appartient à cette première génération aux mains propres et la dernière aussi car demain... on privatise. Crespo connaît la victime. Il est intrigué par cette pétoire retrouvée sur Pedro, lui qui tout au long de sa longue existence militante n'a jamais tiré un seul coup de feu ou eu recours à la violence pour défendre le faible contre le puissant, la justice ou la liberté. Le défunt, maître ès qualités, incarnait la "rigueur morale des anars". 
2 Dans le $\mathrm{n}^{\circ} 1270$ qu'Hommes et Migrations consacrait aux migrations latino-américaines, Fanny Jedlicki abordait la question du retour des exilés au Chili. C'est aussi la toile de fond de ce roman. Un livre enchanteur, comme peuvent l'être les récits d'Albert Cossery, où l'auteur réalise un tour de force : évoquer les années de dictature, les luttes passées, l'optimisme d'une "jeunesse partie en lambeaux", l'exil des uns, les tortures ou la mort des autres, le difficile retour des exilés dans un pays méconnaissable, à la" normalité factice"... dans une sorte de clair-obscur émotionnel et littéraire où l'humour, l'élégance et la légèreté, émergeant du brouillard de l'Histoire, dominent.

"Les anciens exilés étaient désorientés (...). Sans les prévenir on avait changé le pays." Qu'ils débarquent de Berlin, comme Conception et Coco, de Paris comme Cacho Salinas ou d'un périple plus chaotique comme Lolo Garmendia, ces "vétérans", "naufragés d'un même bateau" sont deux fois exilés. En Europe, ils ont laissé qui une femme qui un enfant "aux racines aériennes". Au Chili, les valeurs portées par ces magnifiques spécimen d'une humanité d'avant la mondialisation à la sauce libérale des marchés - et des esprits -, vont à contre-courant d'une société qui déshabille les filles du peuple pour vendre un peu plus de (mauvais) café à des consommateurs mi voyeurs mi amorphes. Alors oui, cela vaut sûrement la peine, peut-être une dernière fois, de "tenter le coup", c'est-à-dire de "faire son devoir" et d'arrêter, même un bref instant, la pluie sur Santiago.

4 Il faut lire, toute affaire cessante, L'Ombre de ce que nous avons été. Des ombres qui “ existeront aussi longtemps qu'il y aura de la lumière". 